\title{
PARA UMA GENEALOGIA DA ESCOLA PRIMÁRIA RURAL: ENTRE O ESPAÇO E A CONFIGURAÇÃO PEDAGÓGICA (SÃO PAULO, 1889-1947) ${ }^{1}$
}

\section{FOR A RURAL ELEMENTARY SCHOOL GENEALOGY: BETWEEN THE SPACE AND THE EDUCATIONAL SETTING}

\begin{abstract}
Rosa Fátima de Souza*
Professora adjunta da Universidade Estadual Paulista Júlio de Mesquita Filho, no Departamento de Ciências da Educação e Professora do Programa de Pós-graduação em Educação da Faculdade de Filosofia e Ciências da Unesp, campus de Marília Virgínia Pereira da Silva de Ávila**

Professora adjunta da Universidade de Pernambuco, campus Petrolina, no Colegiado de Pedagogia; Coordenadora do Programa de Pós-graduação Formação de Professores e Práticas Interdisciplinares
\end{abstract}

Resumo: Neste artigo problematiza-se a configuração da escola primária rural no Estado de São Paulo, no período de 1889 a 1947. Partindo do exame dos princípios de classificação adotados pelos órgãos da administração do ensino - nível de formação de professores, duração do curso primário, abrangência dos programas de ensino, localização das escolas e propostas pedagógicas -, discute-se no estudo sobre a produção da diferença entre a escola primária urbana e rural e a definição de propostas pedagógicas específicas que consolidaram uma identidade para as escolas rurais, muito além da localização espacial.

Palavras-chave: História da educação. Educação rural. História da educação rural. Escola primária rural. Ensino típico rural.

Abstract: In this article it is discussed the configuration of the rural primary school in the State of São Paulo, in the period from 1889 to 1947. Based on the examination

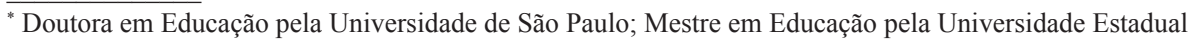
de Campinas.

** Doutora em Educação Escolar pela Universidade Estadual Paulista Júlio de Mesquita Filho; Mestre em Educação pela Universidade do Estado de Santa Catarina.
} 
of the classification principles adopted by the management bodies of the school-teacher training level, duration of primary education, coverage of educational programs, location of schools and educational proposals - it is discussed in the study about the production of the difference between the urban and the rural primary schools and the definition of specific educational proposals that consolidated an identity for rural schools beyond the spatial location.

Keywords: History of the Education. Rural education. History of the rural education. Rural primary school. Typical rural teaching.

\section{INTRODUÇÃO}

O exame dos princípios de classificação das escolas primárias no Estado de São Paulo, em perspectiva histórica, põe em evidência a problemática relação entre escola e diferenciação social e o jogo complexo de produção da racionalidade administrativa e pedagógica do sistema de ensino. O objetivo neste texto é problematizar esse processo de produção da diferença, destacando, especialmente, a lenta configuração da escola primária rural, considerando as políticas educacionais que corroboraram a diversificação das escolas. A análise mostra como a diferenciação das escolas - pelo nível de formação dos professores - deslocou-se gradativamente para a distinção espacial, e desta para a diferenciação pedagógica. A partir da década de 1910, rural e urbano tornaram-se categorias fundamentais para se conceber a organização do ensino e para se legitimarem propostas educacionais diferenciadoras.

Vinculada intrinsecamente à história da escola primária isolada, a escola primária rural foi se delineando no Estado de São Paulo como um constructo histórico, configurada como tal somente nos anos 1940. Nessa trajetória é possível perceber deslocamentos de sentidos importantes, como buscaremos demonstrar. Para tanto, utilizamos as mensagens dos governadores, a legislação do ensino, os Anuários do Ensino do Estado de São Paulo e os anais da Conferência Interestadual do Ensino Primário como fontes documentais.

O texto inicia examinando as primeiras reformas da instrução pública, implementadas no Estado de São Paulo no período republicano. Destacamos como as escolas preliminares foram, inicialmente, alvo da modernização do ensino até se converterem em escolas isoladas, momento em que ocuparam um lugar secundário no sistema de ensino primário. Na sequência, examinamos o lento processo de diferenciação espacial das escolas isoladas no período entre 1904 e 1930, assinalando as implicações dessa mudança. Por último, o texto evidencia a consolidação da escola 
primária rural no Estado de São Paulo nas décadas de 1930 e 1940, assinalando como a diferenciação espacial se converte em propostas pedagógicas específicas e inovadoras relacionadas ao ruralismo pedagógico.

\section{DAS ESCOLAS PRELIMINARES ÀS ESCOLAS ISOLADAS: A DIFERENCIAÇÃO FUNDADA NO PROFESSOR E NA ORGANIZAÇÃO DO ENSINO}

A prática de classificação das escolas elementares não foi uma inovação republicana no Brasil. Desde o século XIX, os governos provinciais adotaram algum tipo de classificação para facilitar o provimento dos professores e para estabelecer o local de criação e instalação de escolas de primeiras letras. Assim, foi recorrente a distinção entre os sexos - escola feminina, masculina e mista - e a diferenciação das escolas pela extensão dos programas de ensino ou localização. Nesses casos, a classificação obedecia mais a um princípio organizacional. Já no século XX, verifica-se o aprofundamento de uma lógica de racionalização administrativa articulada com a diferenciação espacial e social. O modo como isso ocorreu no Estado de São Paulo é o que buscaremos demonstrar.

A primeira reforma republicana da instrução pública no Estado de São Paulo estabeleceu a diferenciação entre as escolas primárias com base na titulação dos professores. A Lei n. 88, de 08 de setembro de 1892, regulamentada pelo Decreto n. 144B, de 30 de dezembro desse ano, estabeleceu que o ensino primário teria a duração de oito anos, compreendendo dois cursos: o preliminar (quatro anos) e o complementar (quatro anos). O ensino preliminar, destinado à educação de menores de ambos os sexos, de sete anos em diante, seria ministrado em escolas preliminares e suas auxiliares - as escolas intermédias e as escolas provisórias. Em todas as localidades onde existissem de 20 a 40 alunos matriculáveis seria instalada uma escola preliminar.

Eram consideradas preliminares as escolas regidas por professores normalistas, obrigados a cumprir o programa estabelecido na reforma de 1892, e as intermédias eram regidas por professores habilitados por concurso em conformidade com os regulamentos de 1869 e 1887. As escolas regidas por professores interinos (não normalistas) eram obrigadas ao ensino das mesmas matérias e provisórias, sendo examinadas pelos inspetores de distritos. Esse critério de classificação que incidia na formação dos professores buscava adequar as novas disposições sobre o ensino público, calcadas na elevação do nível profissional dos professores, resguardando o direito dos professores públicos em exercício. 
As escolas preliminares foram organizadas de modo muito semelhante às escolas de primeiras letras existentes no final do Império, isto é, como escolas singulares de ensino simultâneo. Nessas escolas, um professor ministrava o ensino primário para crianças de diferentes graus de adiantamento em uma mesma sala de aula. No entanto, a reforma modernizou o curso primário adotando o método intuitivo, considerado o ícone da modernização educacional na época, e ampliando ainda mais os programas de ensino.

Não obstante, a criação dos grupos escolares ${ }^{2}$ - a partir de 1893 - instituiu uma diferenciação fundamental no modo de organização das escolas primárias: a escola graduada e as escolas singulares. Os grupos escolares, formados pela reunião de várias escolas preliminares, compreendiam uma organização escolar mais sofisticada e racional, que pressupunha um edifício escolar com várias salas de aula, além de uma organização pedagógica fundamentada na classificação dos alunos em agrupamentos (classes) homogêneos, na divisão do trabalho docente e na graduação e pressupunha, ainda, a fragmentação dos programas de ensino, na ordenação do tempo escolar e na supervisão do trabalho educativo pelo diretor (SOUZA, 2006).

Os investimentos dos governos paulistas voltaram-se para a expansão dessa modalidade de escola primária, por serem consideradas escolas modernas e mais adequadas para a difusão da educação popular, principalmente nos núcleos urbanos. Consequentemente, solidificaram representações positivas em detrimento das demais escolas preliminares, logo denominadas escolas isoladas.

Além de serem instalados nas sedes dos municípios, os professores dos grupos escolares recebiam salários maiores que os professores das demais escolas preliminares e possuíam melhores condições de trabalho. Pelo menos no Estado de São Paulo, a diferenciação entre esses dois tipos de escolas - escolas graduadas e escolas singulares - teve um papel significativo nas representações dos educadores sobre a qualidade do ensino público e a destinação social da escola primária.

Os problemas das escolas singulares eram os mesmos enfrentados pelos professores de primeiras letras do Império, incansavelmente notificados nos relatórios enviados por eles à Inspetoria da Instrução Pública: além dos baixos salários, as escolas funcionavam em locais impróprios, nas casas dos professores ou em cômodos alugados por eles. Os professores ressentiam-se também de móveis e materiais didáticos. Dessa maneira, havia grande dificuldade de provimento das escolas preliminares no interior do Estado. Para sanar o problema, os inspetores escolares passaram a cogitar a necessidade de classificação das escolas em razão da localidade e não mais com base na titulação dos professores. Essa indicação é perceptível nas mensagens enviadas 
pelos presidentes de São Paulo ao Congresso Legislativo, como consta na mensagem de Rodrigues Alves, apresentada em 1901:

Parece-me, todavia, necessária uma melhor classificação das escolas, de modo que figurem ellas no quadro em razão das localidades que servem e não conforme os títulos dos professores que as regem, assim como uma melhor distribuição dellas pelas diversas zonas do Estado. (SÃO PAULO, 1901, p. 17).

O critério de classificação das escolas pela localização atendia a uma dupla necessidade. Por um lado, racionalizava o provimento de professores com a determinação de critérios mais claros sobre o local de criação de escolas e de normas mais específicas sobre concurso de professores, remoção e direitos trabalhistas. Por outro lado, o governo estadual preconizava o auxílio das Câmaras Municipais no desenvolvimento da instrução pública, desejando repassar para os municípios a responsabilidade pelas escolas localizadas nos bairros e locais de menor povoamento. A classificação espacial, como veremos a seguir, traria outras implicações para o sistema de ensino público paulista.

\section{A DIFERENCIAÇÃO ESPACIAL DAS ESCOLAS ISOLADAS}

Em 1904 foi ratificada no Estado de São Paulo a classificação das escolas primárias de acordo com a localização e o uso legal do termo escola isolada. De acordo com a Lei n. 930, de 13 de agosto, o ensino preliminar seria ministrado em escolas ambulantes, em escolas isoladas situadas em bairros ou distritos de paz e na sede de municípios, nos grupos escolares e na escola modelo preliminar anexa à escola normal da Capital. O regulamento estabelecido para a execução dessa lei (Decreto n. 1.239, de 30 de setembro de 1904) especificou a compreensão de cada uma dessas escolas. Eram consideradas ambulantes as escolas isoladas situadas em bairros vizinhos, servidos por via férrea, que estivessem entre si na distância máxima de $6 \mathrm{Km}$.

As aulas nas escolas ambulantes seriam ministradas alternadamente um dia em cada bairro. Escolas de bairro ou de sede de distrito de paz eram aquelas situadas fora do perímetro urbano estabelecido para a cobrança do imposto predial. As escolas de sede de município eram aquelas situadas dentro do perímetro urbano estabelecido para a cobrança desse imposto.

O regulamento estabelecia, ainda, outras prescrições que permitem entrever a busca de racionalização administrativa na expansão do ensino público. Em relação à localização das escolas, o regulamento ressaltava a necessidade de atendimento 
à conveniência da disseminação do ensino e a importância do núcleo de população escolar. A preocupação com o controle da frequência e com o número mínimo de alunos para a manutenção de uma escola foi permanente na administração do ensino paulista.

Pelo regulamento de 1904, as escolas de bairro e de sedes de distritos de paz estariam permanentemente em concurso, indicando outra medida visando à manutenção do provimento de professores. Por último, o regulamento estabelecia que o ensino nas escolas ambulantes teria a duração de três anos, determinando, assim, uma primeira diferenciação das escolas em razão do tempo de duração do curso primário.

Como se pode perceber, no dispositivo legal ainda não se faz uso do termo rural. Essa classificação recai sobre as escolas de bairro, de distrito de paz e de sede de municípios. Quais os limites geográficos de cada um desses termos? Em que consistia o bairro e quais seriam as suas características? Estaria ele mais próximo ou não das áreas rurais? Sobre a noção de bairro, autores como Barros (2004) e Bezerra (2011) têm posto em evidência os vários sentidos atribuídos ao longo do tempo à palavra, incluindo uma porção de território nas proximidades de um núcleo urbano. $\mathrm{O}$ bairro poderia se referir ao arrabalde ou arraial, o que implicaria considerar um grupo da população situada em localidades separadas ou em um extremo da cidade. Contudo, é possível depreender na documentação o uso do termo escola de bairro. A designação se refere à localização da escola em povoados localizados nos arrabaldes da cidade ou daquelas situadas em zonas consideradas propriamente agrárias ou rurais.

$\mathrm{Na}$ transição do século XIX para o século XX, a direção das políticas de expansão do ensino primário no Estado de São Paulo apresentava uma clara preferência pela instalação dos grupos escolares nos centros urbanos. A rede de escolas desse tipo cresceu rapidamente no Estado, atingindo o número de 195 unidades em 1920 (SOUZA, 2012). Ao mesmo tempo, foi significativo o número de criação de escolas isoladas, mas boa parte delas não chegou a funcionar pela falta de provimento. Costa (1983) afirma que entre 1890 e 1919 foram criadas 4.417 escolas isoladas no Estado de São Paulo, porém, somente um terço delas chegou a ser provida.

A exigência de racionalidade administrativa no provimento das escolas vai dando lugar à diferenciação pedagógica. O passo seguinte foi a diferenciação dos programas de ensino e a redução do tempo de duração das escolas isoladas. Em 1907, o presidente Jorge Tibiriçá, em mensagem apresentada à Assembleia Legislativa, insistia na colaboração dos municípios para o desenvolvimento da instrução pública: “É de toda a conveniência, para o plano de desenvolvimento do ensino, que as escolas situadas nos bairros sejam transferidas às municipalidades, continuando a cargo do Estado as dos distritos de paz e as das sedes de município.” (SÃO PAULO, 1907, p. 334). 
Em relação aos programas de ensino, o presidente reafirmava as indicações que vinham sendo feitas pelos inspetores escolares e pelo diretor-geral da instrução pública: “[...] não só as de bairro, mas mesmo as de sede de município não o comportam, por ser excessivamente pesado e até inexequível. Deve, pois, ser modificado e graduado conforme a natureza de cada classe de escolas: muito modesto para as de bairro, mais desenvolvido para as de cidade.” (SÃO PAULO, 1907, p. 334).

A defesa da simplificação dos programas pode ser também observada nos anos posteriores, nos relatórios dos administradores da instrução pública registrados nos Anuários do Ensino do Estado de São Paulo. Em 1909, por exemplo, o diretor-geral da Instrução Pública, Oscar Thompson, argumentava a favor da simplificação dos programas das escolas isoladas, especialmente aquelas localizadas nos bairros e distritos de paz.

Não sendo possível abolir completamente este typo de escola, ele vae sendo suprimido aos poucos, pelos grandes inconvenientes que apresenta, nas cidades e villas, conservando-se apenas nos bairros e districtos de paz mais afastados dos centros populosos. Onde haja um núcleo de escolas isoladas são ellas reunidas com a feição de grupos escolares em miniaturas e confiadas á direção de um professor.

As escolas isoladas devem ter entre nós, como têm em toda a parte, missão bem simples e modesta, deve, ellas, por isso, dar uma instrucção que corresponda ás necessidades futuras de seus alunos.

Educar em pouco tempo crianças cujos serviços são muito cedo aproveitados pelos paes é, em regra, o papel de taes escolas. (SÃO PAULO, [191?], p. 25).

Essa opinião era também compartilhada por vários inspetores do ensino. A propósito, o inspetor Domingos de Paula e Silva afirmava, em 1909:

Sendo, como sabeis, mais trabalhoso o ensino nestas escolas, pela diversidade das classes e também sendo aquellas que incontestavelmente relevantes serviços prestam porque extingue o analfabetismo levando o saber aos pontos mais remotos do Estado, penso que o seu programma deveria ser mais restricto, abrangendo somente a aprendizagem indispensável, sem preocupações de somenos vantagens para aquelles que nenhuma aspiração tem para a carreira de letras. E, nosso meio, mormente pelo interior do Estado, deveríamos nos aproximar das escolas mantidas pela "Sociedade de Instrucção Elementar" de Liége, cujo programma é: procurar das ás classes inferiores o genero de educação intelectual e moral mais apropriadas ás suas necessidades. (SÃO PAULO, [191?], p. 25). 
O diretor da Instrução Pública, João Chrysostomo B. R. Junior, no relatório apresentado ao Secretário do Interior em 1912, sintetizava as observações feitas nos relatórios dos inspetores escolares sobre os obstáculos à elevação do ensino nas escolas isoladas urbanas e rurais. Em primeiro lugar, destacava a diferença de vencimentos:

Os mingoados vencimentos de $250 \$$, nas primeiras [escolas isoladas urbanas], e mingoadissimos de $200 \$$, nas segundas [escolas isoladas rurais], quando todos reconhecem ter o professor das escolas singulares bem mais alta somma de difficuldade a vencer, bem maiores dificuldades do que os adjunctos de grupos escolares que, entretanto, percebem maiores vencimentos. [...] (SÃO PAULO, 1912a, p. 33).

Diferenciar os programas de ensino significava reconhecer que a escola primária não precisava ser a mesma para as populações urbanas e para as rurais. Para essas últimas, o mais recomendado era o ensino mais simplificado, aligeirado e de feição alfabetizante. Nas representações dos administradores do ensino público, a defesa da diferenciação tinha motivações administrativas, mas, de fato, ela expressava um modo de conceber as populações rurais e urbanas e o sentido da participação delas no desenvolvimento da sociedade paulista e brasileira.

Em 1913 foi estabelecido o Regulamento das escolas de bairro (Decreto n. 2.368, de 14 de abril), estas consideradas escolas preliminares situadas nos centros agrícolas, povoados ou distritos de paz, as quais foram classificadas em duas categorias: as de $1^{\text {a }}$ categoria eram aquelas localizadas a menos de $20 \mathrm{Km}$ de uma estação de estrada de ferro e as de $2^{\text {a }}$ categoria, as demais. O curso dessas escolas teria a duração de dois anos, conforme programa estabelecido no Decreto. Para o provimento das escolas, a lei facultava o concurso de professores diplomados e, extraordinariamente, pessoas estranhas ao professorado público. Estes seriam considerados professores provisórios também submetidos a concurso de prova oral e escrita.

Essa legislação acentuou a diferenciação entre as escolas preliminares, mas ainda não especificava a escola da zona rural. Tal classificação somente foi consolidada em 1917 (Lei n. 1.579, de 19 de dezembro), como se pode conferir a seguir:

São rurais as localizadas nas propriedades agrícolas, nos núcleos coloniais e nos centros fabris distantes de sede de municípios.

As escolas distritais são as situadas em bairros ou sede de distrito de paz.

As escolas urbanas (ou de sede) são as criadas em sede de município. (Lei n. 1.579, de 19/12/1917). (SÃO PAULO, 1917, grifo do autor). 
A legislação estabelecia, ainda, que o curso nas escolas rurais teria a duração de dois anos, devendo o programa de ensino ser adaptado às necessidades da zona em que funcionassem as escolas. $\mathrm{O}$ curso das escolas distritais duraria três anos, e o programa seria mais desenvolvido do que o das escolas rurais. Já o curso das escolas urbanas seria de quatro anos, e o programa abrangeria todo o ensino preliminar. A diferenciação entre escolas urbanas e rurais ocorreu no bojo da propaganda da erradicação do analfabetismo e da nacionalização do ensino intensificadas no pós-guerra. A preocupação com os núcleos de imigrantes deve ser visto como um fator importante nessa diferenciação. Isso pode ser evidenciado na mensagem do presidente Altino Arantes, em 1918. Ao se referir aos benefícios da recém-estabelecida Lei n. 1.579, de 19 de dezembro de 1917, afirmava:

As escolas isoladas, de accordo com a citada lei, estão sendo classificadas em diversas categorias. Para o seu provimento, o Governo tem dado preferência aos municípios novos ou longínquos, e aos que são grandes núcleos de população extrangeira ou se encontram menos providos de instrucção.

Dentro em pouco, serão installadas as escolas ruraes, que deverão funccionar nos centros agrícolas, onde a população escolar é, em grande parte, sinão em sua totalidade, descendentes de extrangeiros. A acção do Estado, que até agora se fazia sentir melhor nos centros urbanos, passará a ser exercida, com igual intensidade, na zona rural, até agora menos favorecida.

Sem despreoccupar-se das cidades, onde as escolas já satisfazem às necessidades de sua população, vae o Estado convergir todos os seus esforços, em prol da disseminação do ensino, em pontos remotos, em quem elle se torna mais necessário, quer para os descendentes de extrangeiros, procurando dest'arte integral-os na vida política do paiz, quer para os núcleos de população nacional, proporcionando a seus habitantes os elementos de que carecem, para se tornarem também factores de nosso progresso econômico. (SÃO PAULO, 1918, p. 7-8).

Pode-se dizer que desde o início da República, a escolarização da população rural foi contemplada nas políticas de expansão do ensino elementar no Estado de São Paulo. No entanto, isso ocorreu de forma secundarizada, sem a adoção de medidas efetivas que pudessem sanar os problemas crônicos de provimento das escolas e de condições efetivas para o seu funcionamento. 


\section{PROPOSTAS PEDAGÓGICAS PARA AS ESCOLAS TÍPICAS RURAIS}

A questão do ensino primário rural esteve em debate na sociedade brasileira desde o século XIX. Ao longo da Primeira República, o ruralismo, compreendendo representações e práticas acerca do mundo rural, foi propugnado por vários intelectuais, especialmente Alberto Torres. No âmbito da educação, datam desse período as primeiras propostas de adequação da escola às peculiaridades do meio rural. Na Conferência Interestadual do Ensino Primário, realizada em 1921, o ensino primário rural foi debatido, verificando-se posições antagônicas em relação às finalidades e orientação das escolas localizadas nas zonas rurais. Mais que a defesa de uma escola com características específicas para o campo, a comissão responsável pela discussão do tema se voltou para a questão dos programas de ensino, optando pela sua simplificação.

Em São Paulo, no início dos anos 1920, a reforma Sampaio Dória reduziu o ensino primário para dois anos de duração e unificou os programas das escolas isoladas urbanas e rurais. Dessa maneira, a reforma efetuou uma alteração importante. Na visão do reformador, a classificação das escolas isoladas em rurais e urbanas constituía um dado puramente formal. O programa deveria ser instrutivo e idêntico para todas as escolas, no entanto, para aquelas localizadas no campo, ele indicava a integração das matérias com um programa de pequenas indústrias agrárias, isto é, uma escola alfabetizante e com objetivo profissional, visando conter o êxodo rural (CONFERÊNCIA INTERESTADUAL DE ENSINO PRIMÁRIO, 2003).

A reforma iniciada em 1920 permaneceu em vigência até 1924. Em 1921, com a saída de Sampaio Dória, o professor Guilherme Kuhlmann assumiu a Inspetoria da Instrução Pública. Ao contrário daquele, que considerava a criação de escolas isoladas rurais um elemento de fundamental importância na campanha de alfabetização, Kuhlmann apostou na criação de escolas reunidas. Assim, em 1923, havia no Estado de São Paulo 199 grupos escolares, 348 escolas reunidas, 1.633 escolas isoladas, 10 escolas normais oficiais, quatro profissionais e três ginásios públicos (SÃO PAULO, 1923, p. 24).

Nos anos 1930 e 1940, a ruralização do ensino ganhou força advogada por alguns intelectuais e educadores que passaram a defender uma escola com características e finalidades específicas para a zona rural. Em São Paulo, o principal representante do ruralismo foi Sud Mennucci, cuja atuação foi notável (MONARCHA, 2007; VICENTINI; GALLEGO, 2006). Entre 1931 e 1946, esse educador ocupou por três vezes o cargo de diretor geral do ensino, ocasiões em que buscou reformar a educação 
pública paulista em conformidade com os ideais ruralistas, defendendo instituições escolares com feição ruralista, isto é, com propostas pedagógicas direcionadas para o meio rural. Nesse sentido, Sud defendeu a formação especializada para o magistério rural (criação de escolas normais rurais) e a instalação de grupos escolares no campo e de escolas isoladas vocacionais rurais (MENNUCCI, 1932).

Pode-se dizer, portanto, que foram nas décadas de 1930 e 1940 que começaram a se delinear propostas pedagógicas específicas para o ensino primário rural, no Estado de São Paulo.

No início da década de 1930, apesar das tentativas malogradas de Sud Mennucci de reformar a educação rural, permaneceram na educação pública paulista as proposições estabelecidas pelo Código de Educação de 1933 (Decreto n. 5.884, de 21 de abril), elaborado na gestão de Fernando de Azevedo na Diretoria do Ensino de orientação marcadamente escolanovista (ÁVILA, 2013). O Código incorporou, de certa forma, algumas propostas em circulação sobre o ensino primário rural, mas não deu ao tema ênfase e tratamento específico.

As escolas públicas primárias foram ordenadas em quatro categorias: escolas isoladas, grupos escolares, cursos populares noturnos e escolas experimentais (SÃO PAULO, 1933). As escolas rurais foram tratadas na seção destinada às escolas isoladas. Nesse sentido, o Código previu instalações mais adequadas a seus fins para essas escolas, visando estabilizar o professor pelas condições materiais de conforto. Além disso, indicou a possibilidade de as escolas da zona rural adotarem gradualmente o tipo de granja-escolar, com área cultivável de, pelo menos, três hectares, contendo um edifício com salas de aula e aposentos necessários à residência do professor.

Para auxiliar o trabalho na granja escolar, a legislação previa as Missões Técnicas e Culturais, que seriam “[...] criadas, na medida das possibilidades econômicas [...] que visitarão periodicamente cada uma das escolas rurais, para estimular e orientar a atividade do professor." (SÃO PAULO, 1933, p. 72-73). Inspiradas nas missões técnicas e culturais do México, iniciadas em 1922, o objetivo das missões era prestar assistência técnica aos professores, subsidiá-los com materiais de estudo e de trabalho, o que incluía desde biblioteca e aparelhos de projeção e de radiotelefonia, até instrumentos agrícolas, mudas e sementes.

Quanto ao programa para as escolas isoladas rurais, o ensino deveria ser “[...] essencialmente prático e encaminhado no sentido de fixar o indivíduo no meio em que vivia, sobretudo, adaptado às necessidades e conveniências locais." (SÃO PAULO, 1933, p. 65). As matérias permaneceram as mesmas em vigor nas reformas anteriores: o ensino da Leitura, Linguagem Oral e Escrita, Aritmética e Geometria, 
Geografia, História do Brasil e Instrução Cívica, Ciências Físicas e Naturais, Trabalhos Manuais, Desenho, Caligrafia, Canto e Ginástica (SÃO PAULO, 1933). Tomando como referência as orientações metodológicas da Escola Nova e/ou Escola Ativa, a execução do programa previa um ensino com ênfase na observação e na experimentação, com métodos diversificados e modernos.

Ainda nos anos 1930, começaram a ser criados os primeiros grupos escolares rurais no Estado de São Paulo, e nos anos 1940, as escolas isoladas típicas rurais com orientação ruralista (MOTA, 2010; MORAES, 2014). A expansão das escolas primárias rurais foi também significativa nas décadas entre 1930 e 1960. Em 1930, o Estado de São Paulo contava com: 309 grupos escolares atendendo 198.340 alunos; 205 escolas reunidas, com 37.868 alunos matriculados; 630 escolas isoladas urbanas, com 29.947 alunos; e 2.218 escolas isoladas rurais, com 90.137 matriculados (SÃO PAULO, 1931).

No ano 1957, o Estado contava com 7.225 unidades de escolas isoladas, sendo a maioria localizada na zona rural, 161 escolas isoladas típicas rurais e 49 grupos escolares rurais. Além disso, a rede de escolas primárias públicas compreendia 1.462 grupos escolares localizados nas zonas urbanas e 1.161 classes e escolas de emergência (SÃO PAULO, 1958, p. 91).

Passados 14 anos da publicação do Código de Educação (SÃO PAULO, 1933), e em meio ao clima de redemocratização política, o Governador Adhemar de Barros (1947-1951) aprovou a Consolidação das Leis de Ensino do Estado de São Paulo (Decreto n. 17.698, de 26 de novembro de 1947), tendo à frente do Departamento de Educação o professor Raul de Carvalho Guerra, Diretor-Geral Substituto. Essa legislação incorporou de forma mais explícita os princípios ruralistas, instituindo uma diferenciação inédita no ensino público paulista, isto é, distinguindo educação primária de educação rural, que passaram a ser tratadas como modalidades distintas.

A educação primária seria ministrada nas escolas isoladas, nos grupos escolares e nos cursos primários anexos às escolas normais, no curso primário de cinco anos - subdividido em primário comum de quatro anos e complementar de um ano, este oferecido no Instituto de Educação "Caetano de Campos" e nos cursos populares noturnos (SÃO PAULO, 1948). Já a educação rural seria ministrada nas escolas típicas rurais, nos grupos escolares rurais, nos cursos de agricultura das escolas normais e nos cursos especiais intensivos destinados aos professores, com ou sem função no magistério oficial (SÃO PAULO, 1948).

Não houve alterações no programa de ensino, permanecendo as matérias vigentes desde 1933: Leitura, Linguagem Oral e Escrita; Aritmética e Geometria; Geografia, História do Brasil e Instrução Cívica; Ciências Físicas e Naturais; Trabalhos 
Manuais, Desenho, Caligrafia, Canto e Ginástica. No desenvolvimento do programa, permaneceram as prescrições do Código de Educação, isto é, o ensino nas escolas isoladas rurais continuaria essencialmente prático e encaminhando no sentido de fixar o indivíduo no meio em que vivia e adaptado às necessidades e conveniências locais (SÃO PAULO, 1948).

Igualmente, foram mantidas as missões técnicas e culturais, porém, não deveriam ultrapassar 60 professores, entre os quais um professor com diploma de educador sanitário, dois técnicos de trabalhos agrícolas, um professor encarregado dos trabalhos de extensão cultural no meio social a que serve a escola e um inspetor especializado nos problemas de educação rural (SÃO PAULO, 1948).

Assim, da perspectiva normativa, a Consolidação das Leis do Ensino do Estado de São Paulo de 1947 reiterou a existência, de fato, de dois tipos de ensino primário ministrado nas zonas rurais do Estado: o ensino comum, mantido na maioria das escolas isoladas, e o ensino típico rural, com objetivos e programas direcionados ao meio ministrado em grupos escolares rurais, granjas escolares e escolas isoladas típicas rurais.

Dessa maneira, torna-se relevante interrogar tanto a produção histórica dos critérios de classificação das escolas primárias quanto as disputas políticas e as lutas de representações sobre a educação e a população rural.

\section{CONSIDERAÇÕES FINAIS}

O acesso das populações rurais à escola elementar foi um processo lento no Brasil. O "privilegiamento" das populações urbanas foi uma característica marcante da expansão do ensino público elementar na primeira metade do século XX.

A configuração da escola rural ocorreu, inicialmente, pelo reconhecimento de uma diferença espacial, ainda que a simplificação dos programas e a redução do tempo de duração do ensino primário esquadrinhassem contornos de uma diferença pedagógica significativa.

Com ênfase em um modelo de escolarização voltado para os aspectos da vida urbana, as políticas educacionais no Estado de São Paulo dirigiram-se muito mais às cidades do que à zona rural. Não por acaso, os índices de alfabetização e técnicas de trabalhos mostravam-se superiores nas zonas urbanas. Em grande parte das escolas primárias rurais, permaneceram determinados fatores como concorrentes para a baixa produtividade do ensino expressa nos altos níveis de evasão e repetência, 
no nível de qualificação dos professores - quase todos leigos -, na precariedade das instalações escolares e na falta de material e de equipamento.

Em relação às concepções de ensino, houve oscilação entre a adoção do modelo de escola difundido nos centros urbanos e outro modelo específico para a zona rural, debate que se intensificou entre os anos 1930 e 1940, particularmente no Estado de São Paulo. Nesse Estado, coexistiram, no período mencionado, dois tipos de escola primária rural: as escolas isoladas e grupos escolares localizados na zona rural, cujo programa era o mesmo das escolas urbanas, e as escolas isoladas e grupos escolares típicos rurais, com uma organização de ensino de caráter vocacional-agrícola.

Nesse texto, buscamos demonstrar que as políticas para as escolas primárias rurais no Estado de São Paulo iniciaram na Primeira República, mas os projetos pedagógicos específicos para a educação rural foram consubstanciados no final dos anos 1940. Nessa trajetória, a produção da diferença entre escolas urbanas e rurais operou pela negatividade das segundas e pelo acirramento do processo de diferenciação educacional e social.

A análise dos princípios de classificação das escolas primárias permite apreender a produção das diferenças e desigualdades educacionais e sociais. O rural como categoria espacial e/ou pedagógica põe em questão a necessidade de uma historiografia mais atenta aos projetos de institucionalização da escolarização da infância no meio rural e às políticas governamentais para a educação no campo.

Notas explicativas:

${ }^{1}$ As reflexões neste artigo (apresentado originalmente no VII Congresso Brasileiro de História da Educação, realizado em Cuiabá, MT) foram elaboradas com base no desenvolvimento de dois projetos de pesquisa: História da Escola Primária no Brasil: investigação em perspectiva comparada em âmbito nacional (1930 1961), financiado pelo CNPq, e História da Escola Primária Rural no Estado de São Paulo (1931 1968): circulação de referenciais estrangeiros, iniciativas do Poder Público e cultura escolar, financiado pela FAPESP.

${ }^{2}$ De acordo com a Lei Orgânica do Ensino Primário, publicada em 1946, os estabelecimentos de ensino primário mantidos pelos poderes públicos foram designados como: Escola isolada (R.I.), Escola Reunida (E.R), Grupo Escolar (G.E) e Escola Supletiva (E.S). Eram consideradas escolas isoladas aquelas que possuíam somente uma turma de alunos, entregue a apenas um docente. As escolas isoladas e as escolas reunidas ministrariam somente o curso elementar; os grupos escolares, por sua vez, poderiam ministrar o curso elementar e o curso complementar, e as escolas supletivas, apenas o curso supletivo.

\section{REFERÊNCIAS}

ÁVILA, V. P. da S. História do ensino primário rural em São Paulo e Santa

Catarina (1921-1952) - uma abordagem comparada. 2013. Tese (Doutorado em Educação Escolar)-Faculdade de Ciências e Letras, Universidade Estadual Paulista, Araraquara, 2013. 
BARROS, S. A. L. A escala bairro e o conceito de lugar urbano: o caso de apipucos e poço da panela no Recife. Pós, Revista do Programa de Pós-Graduação em Arquitetura e Urbanismo da Fauusp, n. 15, p. 56-74, jun. 2004. Disponível em: $<$ http://www.revistas.usp.br/posfau/article/view/43372>. Acesso em: 15 maio 2015.

BEZERRA, J. A. Como definir o bairro? Uma breve revisão. GEOTemas, Pau dos Ferros, v. 1, n. 1, p. 21-31, jan./jun. 2011. Disponível em: <http://ojs.uern.br/index. php/geotemas/article/viewFile/118/109>. Acesso em: 08 fev. 2013.

CONFERÊNCIA INTERESTADUAL DE ENSINO PRIMÁRIO, 12., 2003, Rio de Janeiro (1921). Anais... Pelotas: FAE/ UFPel, 2003.

COSTA, A. M. C. I. da. A escola na República Velha: expansão do ensino primário em São Paulo. São Paulo: EDEC, 1983.

MENNUCCI, S. O que fiz e pretendia fazer. São Paulo: Piratininga, 1932.

MONARCHA, C. Cânon da reflexão ruralista no Brasil: Sud Mennucci. In: WERLE, F. O. C. (Org.). Educação rural em perspectiva internacional: instituições, práticas e formação do professor. Ijuí: Ed. Unijuí, 2007.

MORAES, A. I. D. Ensino primário tipicamente rural no estado de São Paulo: granjas escolares, grupos escolares rurais e escolas típicas rurais (1933-1968). 1. ed. São Paulo: Cultura Acadêmica, 2014.

MOTA, A. Higienizando a raça pelas mãos da educação ruralista: o caso do Grupo Escolar Rural do Butantan em 1930. Interface, Botucatu, v. 14, n. 32, p. 9-22, mar. 2010. Disponível em: <http://www.scielo.br/scielo.php?script=sci arttext\&pid=S1414-32832010000100002\&lng=en\&nrm=iso $>$. Acesso em: 15 maio 2015.

SÃO PAUlO (Estado). Anuário do Ensino do Estado de São Paulo de 1910. Publicação organizada pela Diretoria Geral da Instrução Pública por ordem do governo do Estado. 1910-1911. São Paulo: Typographia Siqueira, Nagel \& C, [1912a].

SÃO PAUlO (Estado). Anuário do Ensino do Estado de São Paulo: 1909-1910. Publicação organizada pela Inspetoria Geral do Ensino por ordem do governo do Estado. São Paulo: Tipografia do Diário Oficial, [191?].

SÃo PAUlO (Estado). Anuário do Ensino do Estado de São Paulo. Relatório apresentado ao Exmo. Snr. Dr. Secretário do Interior pelo diretor geral da Instrução Pública Guilherme Kuhlmann. São Paulo: Imprensa Official, 1923. 
SÃO PAULO (Estado). Decreto n. 2.225, de 16 de abril de 1912. Manda observar a consolidação das leis, decretos. Consolidação das Leis e Decretos do Estado de São Paulo. São Paulo: Typ. do Diário Official, 1912.

SÃO PAULO (Estado). Decreto n. 5.884, de 21 de abril de 1933. Institui o Código de Educação do Estado de São Paulo. Secretaria da Educação e da Saúde. São Paulo: Imprensa Oficial do Estado, 1933.

SÃO PAULO (Estado). Decreto n. 17.698, de 26 de novembro de 1947. Aprova a Consolidação mandada elaborar pelo decreto n. 17.211, de 13 de maio de 1947. Coleção das Leis e Decretos do Estado de São Paulo de 1947. São Paulo: Imprensa Oficial do Estado, 1948. v. 1. T. 58. $4^{\circ}$ trimestre.

SÃO PAULO (Estado). Directoria Geral do Ensino. Estatística Escolar de 1930. Secção de Estatística e Archivo. São Paulo: Imprensa Oficial, 1931. v. 1.

SÃO PAULO (Estado). Lei n. 88, de 08 de setembro de 1892. Colecção de Leis e Decretos do Estado de São Paulo, 1892.

SÃO PAULO (Estado). Mensagem apresentada ao Congresso Legislativo do Estado, em 07 de abril de 1901, pelo Presidente do Estado Francisco de Paula Rodrigues Alves. São Paulo: Typographia do Diário Official, 1901. Disponível em: $:<$ http://www.pps.crl.edu/brazil/provincial $>$. Acesso em 02 jun. 2015.

SÃO PAULO (Estado). Mensagem apresentada ao Congresso Legislativo do Estado, em 14 de julho de 1907, pelo Presidente do Estado Jorge Tibiriçá, Bernardino de Campos. São Paulo: Typographia do Diário Official, 1907.

SÃO PAULO (Estado). Mensagem apresentada ao Congresso Legislativo, em 14 de julho de 1918, pelo Dr. Altino Arantes, Presidente do Estado de São Paulo. 1918. Disponível em: <http://brazil.crl.edu/bsd/bsd/u1175/000001.html >. Acesso em: 02 jun. 2015.

SÃO PAULO (Estado). Mensagem apresentada pelo Governador Jânio Quadros à Assembleia Legislativa do Estado de São Paulo em 14 de março de 1958. São Paulo: [s. n.], 1958.

SOUZA, R. F. de. Alicerces da Pátria: escola primária e cultura escolar no estado de São Paulo (1890-1976). 2006. 367 p. Tese (Livre docência)-Faculdade de Ciências e Letras, Universidade Estadual Paulista Júlio de Mesquita Filho, Araraquara, 2006. 
SOUZA, R. F. de. As escolas públicas paulistas na Primeira República: subsídios para a história comparada da escola primária no Brasil. In: ARAUJO, J. C. S.; SOUZA, R. F.; PINTO, R. N. (Org.). Escola primária na Primeira República (1889-1930): subsídios para uma história comparada. 1. ed. Araraquara: Junqueira \& Marin, 2012.

VICENTINI, P. P.; GALLEGO, R. de C. Escolas primárias urbanas e rurais: um estudo dos debates acerca de suas especificidades na organização do sistema de ensino paulista (1890-1945). In: CONGRESSO BRASILEIRO DE HISTÓRIA DA EDUCAÇÃO, 4., 2006, Goiânia. Anais... Goiânia: SBHE, 2006. Disponível em: <http:// www.sbhe.org.br/novo/congressos/cbhe4/individuais-coautorais/eixo02/Paula $\% 20$ Perin\%20Vicentini\%20e\%20Rita\%20de\%20Cassia\%20Gallego\%20-\%20Texto. pdf>. Acesso em: 03 mar. 2010.

Recebido em: 14 de junho de 2015 Aceito em: 17 de agosto de 2015

Endereço para correspondência: Avenida Vicente Ferreira, 1278, Cascata, 17515000, Marília, São Paulo, Brasil; virginia.avila@upe.br 
